Article

\title{
From Awe to Ecological Behavior: The Mediating Role of Connectedness to Nature
}

\author{
Yan Yang ${ }^{1}$, Jing $\mathrm{Hu}^{2, *}$, Fengjie Jing ${ }^{2, *}$ and Bang Nguyen 2 (i) \\ 1 School of Sports Science and Engineering, East China University of Science and Technology, \\ Shanghai 200237, China; yangyan@ecust.edu.cn \\ 2 School of Business, East China University of Science and Technology, Shanghai 200237, China; \\ bang.london@gmail.com \\ * Correspondence: hujingwgy@foxmail.com (J.H.); fjjing@ecust.edu.cn (F.J.)
}

Received: 19 June 2018; Accepted: 13 July 2018; Published: 16 July 2018

check for updates

\begin{abstract}
Awe is a self-transcendent emotion that can diminish one's focus on the self and serves as an important motivator of commitment to social collectives. However, the influence of awe on ecological behavior is not clear. This study examines the relationships between people's feeling of awe, their connectedness to nature, and ecological behavior. Three experiments tested the effect of awe on ecological behaviors including mediation tests. Compared with participants in the control condition, participants in the awe condition were more inclined to behave ecologically (Study 1 and 2) and reported a higher feeling of connectedness to nature (Study 2). Moreover, the relationship between awe and ecological behavior was mediated by connectedness to nature (Study 3 ). These findings indicate that awe helps broaden the self-concept by including nature and increase connectedness to nature, which in turn lead to ecological behavior. They also highlight the significance of connectedness in explaining why awe increases ecological behavior.
\end{abstract}

Keywords: awe; connectedness to nature; ecological behavior; self-concept

\section{Introduction}

Global environmental protection agencies and governments spare no efforts to advocate eco-friendly actions and encourage individuals to behave ecologically. In this context, studying individuals' ecological behavior has become a popular topic, as it is broadly approved that endeavors to alter behaviors that are harmful to the environment can help solve environmental problems worldwide. Many scholars are engaging in research to discover ways to increase ecological behavior from varying perspectives [1,2]. However, people's relevant daily practice is not as ideal as the high awareness of ecological behavior. It seems to be easier to just claim an ecological lifestyle for people than to behave ecologically. A national survey of the Chinese ecological civilization shows that the score of actual ecological practice is much lower than ecological awareness [3]. Such a significant gap between ecological awareness and behavior implies that intrinsic mechanism underlying the ecological behavior at individual level has not been fully addressed [4].

In general, people who act ecologically often have to sacrifice their individual interests in exchange for the overall interests of public and society [5]. Due to the loss of self-interest caused by ecological behavior, individuals usually face a trade-off prior to engage in the process of ecological behavior [6]. If some appropriate means were conducted to lower individuals' emphasis on self and increase their attention to the external surroundings, ecological behavior would become more logically reasonable for individuals. The emotion of awe as one typical transcendent experience dissuades individuals from concentrating on immediate personal interest [7] and prompts a broader existential approach of life that leads to the inclination to take into account the welfare of other people, the broader 
community, and nature $[8,9]$. Therefore, the emotion of awe may be an effective breakthrough to prompt ecological behavior.

Many environmental psychologists assert that an individual's relationship with nature is a key antecedent of ecological value, belief and behavior $[10,11]$. For example, connectedness to nature $(\mathrm{CN})$ refers to a self-perceived close association with the natural world. The role of $\mathrm{CN}$ in facilitating the ecological behavior has recently been well acknowledged in literature on environmental psychology [11,12]. Although CN contributes significantly to environment conservation planning and practice [13], the antecedents of $\mathrm{CN}$ are still poorly understood, with research lacking conceptual sophistication and depth. Many scholars focus on external factors, such as exposure to nature, environmental education [14], which fail to present the essential reason for prompting CN. CN is considered to be a self-expression of the need to belong to the external world including nature $[15,16]$. Any factors that expand the self-concept to include nature may influence $\mathrm{CN}$, such as the awe emotion. Individuals experiencing the awe emotion would perceive a smaller self, directing the attention from self to broader external entities $[17,18]$. Therefore, it is indicated that awe would contribute to ecological behavior by increasing the $\mathrm{CN}$.

Guided by these arguments, the present study aims to provide evidence that: (1) awe increases the ecological behavior (Study 1 and 2); (2) awe increases CN (Study 2) and; (3) the 'awe-ecological behavior' relationship is mediated by the effect of CN (Study 3). Three experiments were conducted with participants in China.

\section{Literature Review}

\subsection{Awe and the Connectedness to Nature}

Belonging is a fundamental human need and reliable social relationships are essential to physical and psychological well-being [19]. The connection with nature functions in the same way [20]. It has been proved that the majority of people have the tendency to associate self with natural world [21]. The close association with nature could contribute significantly to prompting individuals' physical, mental, and overall wellbeing caused by exposure to nature [13], for example, Nisbet, Zelenski and Murphy demonstrated that $\mathrm{CN}$ contributes significantly to personal growth, self-acceptance, positive relations with others, and life satisfaction [22]. Meanwhile, nature contact and images of nature are considered to be effective means to cope with negative experiences and feelings in people's lives, mitigating stress, anxiety, and illness [23]. However, the isolation from the outdoor natural environment in modern city life is unable to meet the basic need for connecting with the natural world, which greatly undermines individuals' wellbeing. Therefore, understanding how to re-connect humans and nature is crucial to fulfilling the fundamental physical and psychological demand.

Keltner and Haidt consider awe as a mixed emotional response to perceptually vast stimuli that requires adjusting mental structures that cannot assimilate a new experience [24]. Although various stimuli can inspire awe, from waterfalls to childbirth to senses of devastation, the prototypical awe experience mostly involves encounters with natural phenomena that are immense in size, scope, or complexity [18]. It could be deduced intuitively that awe would have a natural impact on the individual's relationship with nature. This prediction is based on the core features that underlie the awe emotion. Firstly, Shiota, Keltner and Mossman found that both dispositional awe and experimentally elicited awe are related to an emphasis on belonging to 'universal' categories of individuals' self-concepts [17]. The awe emotion tends to make people feel small and insignificant, directing attention from self-interest and concern to entities vaster than the self [18]. Specifically, nature, as one of the primary elicitors of the awe emotion, is the vast surroundings that people could touch and perceive in their daily life. Consequently, it is reasonable to conclude that awe can instigate an individual's feeling of connectedness to larger entities, like nature, by inspiring the perception of the small self. 
Secondly, awe could motivate people to take in new information or enhance people's openness to novel experiences, which has been confirmed to correlate positively with $\mathrm{CN}[18,25,26]$. Since the openness to novel experience could blur the permeable mental boundaries between self and others [27]. It is reasonable to expect that awe could lead to $\mathrm{CN}$, which is characterized by an indistinctness of the perceived boundaries between humans and other living things [15]. The greater the awe emotion individuals experience, the higher the degree of acceptance for external surroundings, including other people, other creatures and objects in nature.

The effect of awe on the feelings of smallness and openness indicates that awe can significantly increase $\mathrm{CN}$. Guided by these results and the above conceptual analysis, the present study examines how awe influences an individual's CN.

\section{2. $\mathrm{CN}$ and Ecological Behavior}

Ecological behavior refers to behavior that aims to minimize the negative effect of people's activities on nature (e.g., saving water, reducing exhaust emission) [4]. Previous studies provide related evidence that a sense of $\mathrm{CN}$ would influence pro-environmental attitudes and ecological behaviors [15,27-29]; for example, farmers with a higher level of CN showed more willingness to protect the local vegetation [12]. There are several theories that help to explain the relationship between $\mathrm{CN}$ and ecological behavior. First, literature that paves the way for our hypothesis involves the study of self-identity. A high level of $\mathrm{CN}$ relates to the expanding self-concept by including nature as part of the self $[28,30]$. Seeing the self as part of the whole life collective could result in the mergence between body and mind with nature [30]. Consequently, protecting natural environments is regarded as self-constructive, since nature is an important component of oneself [15].

The second evidence relates to the study of psychological processes involved in the mechanism of $\mathrm{CN}$ affecting ecological behavior [31]. One of the most significant facets of relationship is dependence [32]. The physical and emotional dependence on nature could predict pro-environmental behavior, as well as inclusion of nature in the self [32]. According to the self-expansion model, when individuals deem nature as a partner of themselves, they would incorporate nature's identity, resources and perspectives into their own [33]. Thus, the feeling of interconnectedness between the self and nature would provoke ecological behaviors due to the consideration of the benefit the natural world.

From the perspective of self-identity and dependence on nature, $\mathrm{CN}$ is suspected to positively affect ecological behavior. Based on this theoretical derivation, we would examine the relationship between $\mathrm{CN}$ and ecological behavior.

\subsection{Awe, $\mathrm{CN}$ and Ecological Behavior}

Because environmental destruction is a bigger-than-self problem, the key values of ecological behavior are the communal, self-transcendent values. These values transcend the focus on the self and prioritize the welfare of other people, the broader community, and nature [9]. The self-transcendent value would lead to intrinsic motives to protect the environment $[34,35]$ while suppressing values that support self-interest. The emotion of awe is deemed to be one typical self-transcendent experience [36]. Hence, people experiencing awe should show intrinsic motives to care for the environment.

The resource allocation theory also provides a foundation for our prediction on the direct relationship between awe and ecological behavior. Given that attention is a limited resource, the more individuals pay attention to themselves, the less they focus on their surroundings [37]. According to the characteristics of awe, individuals who experience awe would reduce focus on self and turn attention to surroundings. Hence, the higher the degree of awe individuals experience, the more consideration they would show for nature. By contrast, the induction of a heightened sense of self-awareness would increase the possibility of self-oriented behavior that contradicts interest in society, such as conspicuous consumption [38]. Consequently, we deduce that the awe emotion directing individual's focus from the self to nature may lead to ecological behavior for the benefit of nature. 
Past studies have documented the social function of awe based on a feeling of self-diminishment; for example, awe can enhance collective concern via a sense of a small self [18]. Awe has also been associated with an improved social relationship with others [39]. It is proposed that self-transcendent emotions like awe can help individuals initiate and maintain relationships with others that facilitate prosocial behavior [39]. Along this line of consideration, we infer that awe could also promote ecological behavior through increased association with nature.

The indirect effect of awe on ecological behavior can be further illustrated by the effect of $\mathrm{CN}$ on ecological behavior, together with the relationship between awe and $\mathrm{CN}$. These lines of study on the awe emotion, $\mathrm{CN}$ and ecological behavior suggest that awe could adjust the self-concept and induce the feeling of $\mathrm{CN}$, which should also increase ecological behavior. We propose that $\mathrm{CN}$ plays an important role in the relationship between awe and ecological behavior. According to previous findings and the present conceptual analysis, we conducted three studies to test the hypotheses that the induction of awe would increase ecological behavior awe by prompting people's feelings of $\mathrm{CN}$.

\subsection{The Current Research}

In the present research, we hypothesize that awe prompts $\mathrm{CN}$ and in turn increases ecological behavior. Three experiments were performed to test these hypotheses (see Table 1). We investigate whether the awe emotion can prompt ecological behavior (Study 1 and 2) and the connectedness to nature (Study 2) and examine the mediation effect of the connectedness to nature on the relationship between awe and ecological behavior (Study 3). We mainly focus on awe induced by natural scenery and powerful people, as physical vastness (e.g., natural sceneries) and social vastness (e.g., a powerful person) are considered to be two typical types of awe elicitors [24,39]. In Study 1, awe is induced by natural sceneries as well as powerful people; in Study 2, awe is induced by powerful people only; in Study 3, awe is induced by natural sceneries only. Varied manipulations of awe were adopted, including recalling report task (Study 1 and 2) and video clips (Study 3). Specifically, emotions (such as fear, pride) and exposure to nature are considered to affect environmentally related behavior $[40,41]$. In light of this concern, we control for other emotional states in Study 1, and induce the awe emotion by a non-natural stimulus in Study 2. We chose college students as participants in our studies. In order to exclude the interferences of other variables such as environmental education and resulting knowledge, all participants were randomly assigned to the awe condition and the control conditions to ensure the homogeneity of other external variables.

Table 1. Aims, materials and method of the three studies.

\begin{tabular}{|c|c|c|c|c|c|}
\hline & \multirow[b]{2}{*}{ Aim } & \multicolumn{3}{|c|}{ Material } & \multirow[b]{2}{*}{ Method } \\
\hline & & $\begin{array}{l}\text { Targeted Emotion } \\
\text { Induction }\end{array}$ & $\mathrm{CN}$ & Ecological Behavior & \\
\hline Study 2 & $\begin{array}{l}\text { 1. Examine the impact of } \\
\text { awe on } \mathrm{CN} \text { and } \\
\text { ecological behavior; } \\
\text { 2. Exclude the influence of } \\
\text { natural elicitors of awe on the } \\
\text { relationship between awe and } \\
\text { ecological behavior. }\end{array}$ & $\begin{array}{l}\text { A narrative } \\
\text { recalling task }\end{array}$ & \multirow[t]{2}{*}{$\begin{array}{l}\text { The Connectedness } \\
\text { to Nature Scale }\end{array}$} & \multirow[t]{2}{*}{$\begin{array}{l}\text { The possibilities to engage } \\
\text { in } 12 \text { ecological behaviors }\end{array}$} & \multirow[t]{2}{*}{ Experiment } \\
\hline Study 3 & $\begin{array}{l}\text { Investigate whether } \mathrm{CN} \\
\text { mediated the effect of awe on } \\
\text { ecological behavior }\end{array}$ & Watching video clips & & & \\
\hline
\end{tabular}

\section{Study 1}

This study investigated the impact of awe on increasing ecological behavior. We predicted that awe would increase the intentions of ecological behavior. Awe and the neutral state were experimentally 
induced via a narrative recall task, which has been well validated and widely adopted by previous research. Ecological behavior was measured by the possibilities to engage in 12 ecological behaviors.

\subsection{Method}

146 Chinese college students in Shanghai were recruited for this experiment. Their major was business management. They received several course credits for their participation, and they ranged in age from 18 to 24 years ( 79 females, $\mathrm{M}_{\mathrm{age}}=22.43, \mathrm{SD}=1.85$ ).

Randomly assigned to one of the two conditions (awe or neutral), all participants were required to recall and describe an experience related to a targeted emotion. The following materials to induce the targeted emotions were adapted from Gordon, Stellar, Anderson, McNeil, Loew and Keltner [39] and Piff, Dietze, Feinberg, Stancato and Keltner [18]. Participants assigned to recall an awe-related experience read the text content as follows.

"We often feel awe in response to vast, beautiful landscapes and natural wonders such as tall mountains, expansive vistas, or large waterfalls. We can also feel awe in response to people who cause large-scale change such as Nelson Mandela and his role in ending apartheid in South Africa. Please take a few moments to recall a time when you felt intense awe like the examples described above."

Participants assigned to recall a neutral experience read the text as follows.

"Bring to mind an ordinary event in your daily life—an event that took place in the last week.

Take a few moments to think about the ordinary event and how it makes you feel."

After that, all participants were instructed to write at least 30 Chinese characters to describe their experience and feeling. Then, participants reported their emotional states, including anger, awe, disgust, fear, pride, sadness, and happiness, assessed by single items ( $1=$ not at all, $7=$ extremely) [18]. Moreover, participants reported the likelihood of engaging in 12 ecological behaviors assessed by the scale developed by Kaiser, Doka, Hofstetter, and Ranney (e.g., "recycling, taking shorter showers"; $\alpha=0.85 ; \mathrm{M}=5.43 ; \mathrm{SD}=0.76 ; 1=$ not at all, $7=$ extremely) [42]. Finally, all participants were thanked.

\subsection{Results}

To ascertain that the recalling task induced the targeted emotion, we contrast the ratings of awe in the awe condition with those in the neutral condition. An independent $t$-test showed that awe induction led to more awe than the control induction, $t(144)=28.75, p=0.000, d=0.93$. Therefore, the awe manipulation was successful (see Table 2 and Figure 1).

Table 2. Mean scores for awe, connectedness to nature, ecological behavior (SDs in Parentheses).

\begin{tabular}{cccccccc}
\hline & \multicolumn{2}{c}{ Study 1 } & \multicolumn{2}{c}{ Study 2 } & \multicolumn{2}{c}{ Study 3 } \\
\cline { 2 - 7 } & Awe & Neutral & Awe & Neutral & Awe & Amusement & Neutral \\
\cline { 2 - 7 } & $(\mathbf{N = 7 5 )}$ & $\mathbf{( N = 7 1 )}$ & $\mathbf{( N = 8 0 )}$ & $\mathbf{( N = 7 8 )}$ & $\mathbf{( N = 8 3 )}$ & $\mathbf{( N = 7 8 )}$ & $\mathbf{( N = 7 7 )}$ \\
\hline Anger & $1.05(0.75)$ & $1.57(1.41)$ & $1.23(0.62)$ & $1.68(1.55)$ & $1.17(0.86)$ & $1.33(0.79)$ & $1.58(1.03)$ \\
Awe & $6.09(0.84)^{* * *}$ & $2.17(0.75)$ & $5.92(0.87)^{* * *}$ & $2.77(0.76)$ & $5.98(0.88)^{\mathrm{b}, \mathrm{c}}$ & $2.20(1.00)^{\mathrm{a}}$ & $2.66(0.89)^{\mathrm{a}}$ \\
Disgust & $1.54(0.76)$ & $2.18(0.83)$ & $1.79(0.76)^{* * *}$ & $2.84(0.77)$ & $2.09(1.21)$ & $1.78(1.14)$ & $2.58(1.09)$ \\
Fear & $2.36(0.98)$ & $2.74(1.12)$ & $2.55(0.84)$ & $2.56(1.12)$ & $2.13(1.11)$ & $1.93(0.94)$ & $2.33(1.27)$ \\
Pride & $4.77(1.45)$ & $4.02(1.21)$ & $4.32(1.02)$ & $4.27(1.17)$ & $4.89(1.37)$ & $4.56(1.02)$ & $4.13(0.87)$ \\
Sadness & $1.18(0.66)^{* * *}$ & $3.09(1.37)$ & $2.68(1.02)$ & $3.13(1.26)$ & $1.12(0.99)^{\mathrm{c}}$ & $1.07(0.78)^{\mathrm{c}}$ & $3.53(0.85)$ \\
Happiness & $5.90(1.20)^{* * *}$ & $4.82(1.61)$ & $5.92(0.76)^{* * *}$ & $4.32(0.88)$ & $5.91(1.12)^{\mathrm{c}}$ & $6.12(1.03)^{\mathrm{c}}$ & $3.24(1.17)$ \\
Amusement & - & - & - & - & $3.79(0.94)^{\mathrm{b}}$ & $5.51(0.88)$ & $3.01(0.87)^{\mathrm{b}}$ \\
\hline
\end{tabular}

Note: For Study 1 and 2: ${ }^{* * *} p<0.001$. For Study 3: ${ }^{\mathrm{a}}$ The means are different from those in the awe condition $(p<0.05){ }^{\mathrm{b}}$ The means are different from those in the amusement condition $(p<0.05){ }^{\mathrm{c}}$ The means are different from those in the control condition $(p<0.05)$. The above emotions are assessed by single items including the text "anger", "awe", "disgust", "fear", "pride", "sadness", "happiness" and "amusement" separately. 


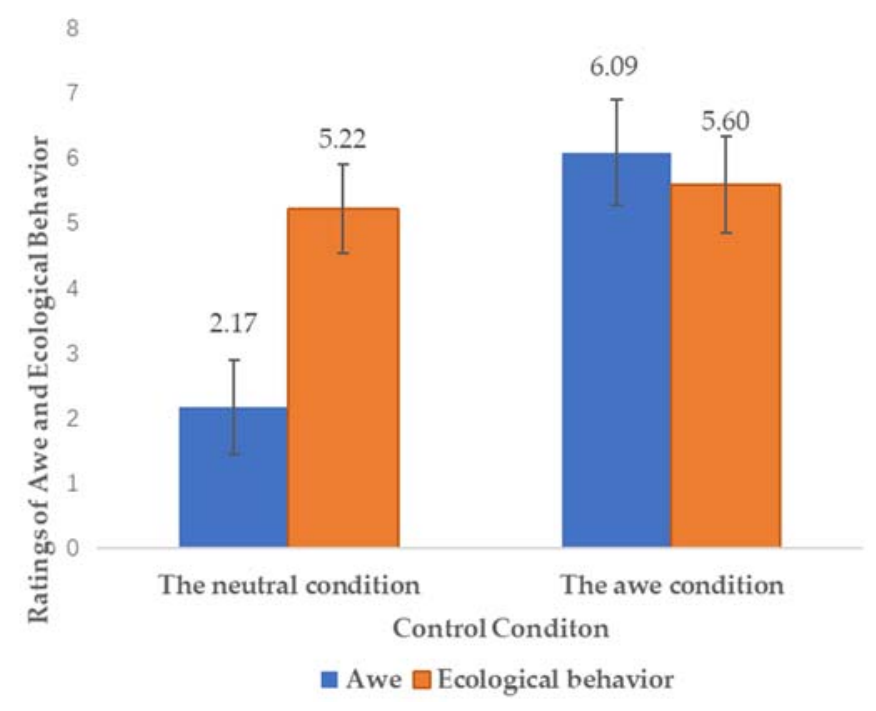

Figure 1. The means and standard deviations of awe and ecological behavior in Study 1.

We set composites for negative affects (anger, disgust, fear, sadness) and positive affects (happiness, pride). An independent $t$ test showed that awe induction led to more positive emotion $(\mathrm{M}=5.34, \mathrm{SD}=0.72)$ than the neutral induction $(\mathrm{M}=4.42, \mathrm{SD}=0.81), t(148)=8.55, p=0.000, d=0.51$. Moreover, the awe induction led to less negative emotion $(\mathrm{M}=1.53, \mathrm{SD}=0.57)$ than the neutral induction $(\mathrm{M}=2.40, \mathrm{SD}=0.79), t(148)=-7.63, p=0.000, d=-0.53$ (see Table 2$)$.

We then contrast the ratings of ecological behaviors in the awe condition with those in the neutral condition. An independent $t$-test yielded a significant difference across conditions. Participants in the awe condition $(\mathrm{M}=5.60, \mathrm{SD}=0.69)$ reported greater likelihoods of engaging in ecological behaviors than did those in the neutral condition $(\mathrm{M}=5.22, \mathrm{SD}=0.74), t(144)=3.20, p=0.002, d=0.26$ (See Figure 1). In order to examine the unique influence of the awe emotion on ecological behavior, we controlled for the influence of other emotions on ecological behavior. Results indicated that the influence of awe on ecological behaviors remained unchanged, $\mathrm{F}(1,144)=7.425, p=0.007$.

\subsection{Discussion}

Study 1 served as experimental evidence for the hypothesis that awe prompted ecological behavior. Controlling for the influence of other emotions, the awe emotion still significantly increased ecological behavior. The results were consistent with prior research that the awe emotion helped enhance collective concern instead of self-interest. However, natural scenery, as a typical elicitor of the awe emotion, was considered to have a significant influence on ecological behavior as well $[15,30]$. Consequently, we conducted the next study to further ascertain the effect of awe on ecological behavior by eliciting the awe emotion with non-natural stimuli.

\section{Study 2}

In Study 2, we still adopted the method of a recall report task to elicit the targeted emotions (awe or neutral). Specifically, in order to exclude the influence of natural elicitors, participants were requested to recall and write about something about a great person to induce the awe emotion. Following that, participants reported their emotional state, $\mathrm{CN}$ and how ecologically they would behave. We predicted that awe induced by non-natural sceneries would increase $\mathrm{CN}$ and ecological behaviors. 


\subsection{Method}

158 Chinese college students from a university in Shanghai participated in this experiment. They received several course credits for their participation. Their ages ranged from 17 to 25 years (81 men; $\mathrm{M}_{\text {age }}=23.38 ; \mathrm{SD}=2.10$ ).

Randomly assigned to the awe or neutral condition, all participants were required to recall and describe some experience related to a targeted emotion. The following material to induce emotions was adapted from Gordon, Stellar, Anderson, McNeil, Loew and Keltner [39] and Piff, Dietze, Feinberg, Stancato and Keltner [18]. Participants assigned to recall an awe-related experience read the text as follows:

"Often we feel awe in response to people who cause large-scale change such as Nelson Mandela and his role in ending apartheid in South Africa. Take a few moments to think about a great person and how he (or she) makes you feel."

The neutral state was induced by the following text:

"Bring to mind an ordinary event in your daily life-an event that took place in the last week.

Take a few moments to think about the ordinary event and how it makes you feel."

After reading the text above, all participants were required to write no less than 30 Chinese characters to describe their experience and feeling. Then, they reported their emotional states, including anger, awe, disgust, fear, pride, sadness, and happiness, which were measured by single items ( $1=$ not at all, $7=$ extremely) [18]. Moreover, participants reported $\mathrm{CN}$ assessed by the scale developed by Mayer and Frantz [15], which has been well validated (e.g., "I often feel a sense of oneness with the natural world around $\mathrm{me}^{\prime \prime} ; 1=$ strongly disagree; $7=$ strongly agree). Finally, participants reported their likelihood of behaving ecologically (e.g., "recycling, taking shorter showers"; $1=$ not at all, 7 = extremely), which was identical to the measure of ecological behavior used in Study 1 [42].

\subsection{Results}

We first test whether the manipulation stimulates the target emotion. As shown in Table 2, the results of an independent $t$-test analysis showed that the awe induction increased awe relative to the neutral induction, $t(156)=60.50, p=0.000, d=0.98$. Therefore, the manipulation was successful (See Table 2 and Figure 2).

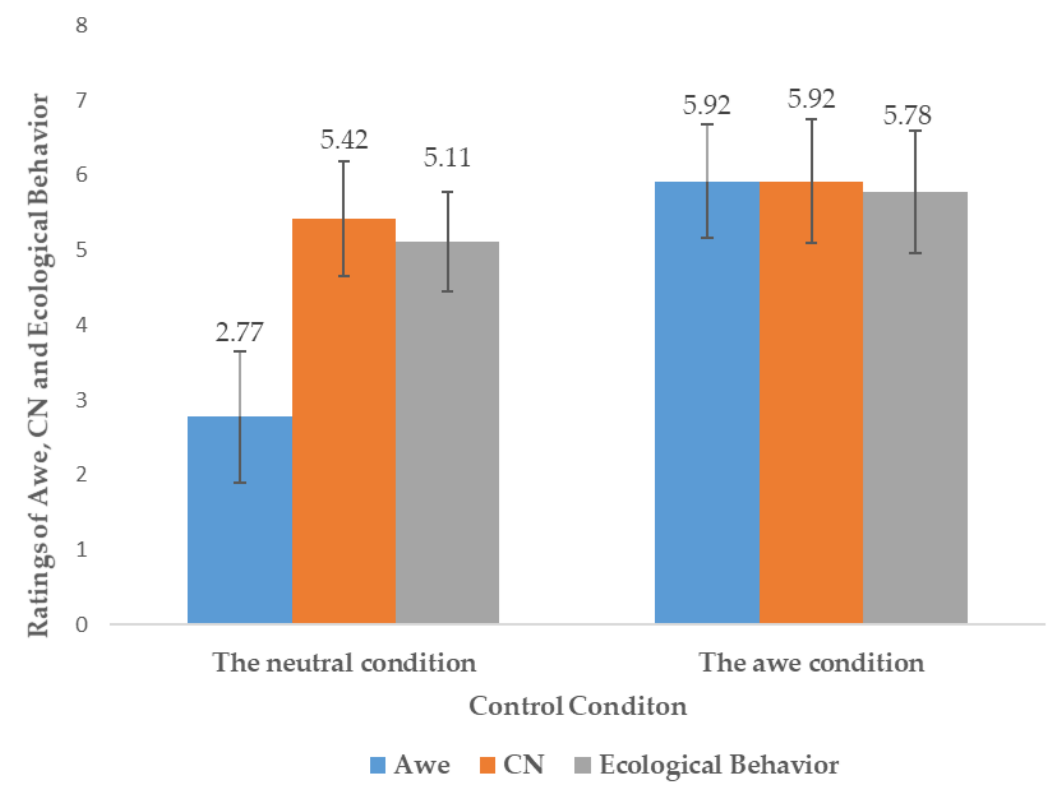

Figure 2. The means and standard deviations of awe, $\mathrm{CN}$ and ecological behavior in Study 2 . 
We then contrast the ratings of $\mathrm{CN}$ and ecological behavior in the awe condition with that in the neutral condition. An independent $t$-test showed that the awe induction increased ratings of $\mathrm{CN}$ $(\mathrm{M}=5.92, \mathrm{SD}=0.77)$ relative to the neutral induction $(\mathrm{M}=5.42, \mathrm{SD}=0.83), t(156)=3.73, p=0.000$, $d=0.29$ (See Figure 2). Moreover, participants in the awe condition has increased likelihoods of behaving ecologically $(\mathrm{M}=5.78, \mathrm{SD}=0.66)$ compared with those in the neutral condition $(\mathrm{M}=5.11$, $\mathrm{SD}=0.82$ ) (See Figure 2), $t(156)=5.63, p=0.000, d=0.41$. Therefore, the induction of awe led to more $\mathrm{CN}$ and ecological behavior than the induction of neutral state.

\subsection{Discussion}

Awe could be induced by anything perceived as possessing vastness, including the natural world [24]. However, nature was confirmed to be a key antecedent of ecological behavior. In order to exclude the impact of nature, awe was manipulated by non-natural stimuli in Study 2. Results indicated that the influence of awe on ecological behavior was still significant. Therefore, Study 2 provided additional evidence that awe could enhance $\mathrm{CN}$ and ecological behavior, even controlling for the influence of natural factors. The following study was conducted to further confirm the mediation effect of $\mathrm{CN}$ on the relationship between the awe emotion and the ecological behavior.

\section{Study 3}

This study investigated whether $\mathrm{CN}$ mediated the effect of awe on ecological behavior. We adopt another method, watching videos, to induce targeted emotional states including awe, amusement and a neutral state. Amusement was chosen as a comparison with awe for the following reasons. First, amusement had been used to compare with the influence of awe in previous research [18]. Then, the two emotions were both in positive valence and induced by "an incongruity between one's expectations and experience" [18]. Finally, the two emotions could both be elicited by nature-related stimuli, which helps confirm the unique effects of awe on ecological behavior, excluding the influence of natural factors [18].

\subsection{Method}

238 Chinese college students in a university in Shanghai were recruited for the study. In addition, they were rewarded with several course credits. Their age ranged from 17 to 25 years (118 men; $\mathrm{M}_{\text {age }}=22.14 ; \mathrm{SD}=1.76$ ).

Randomly assigned to the awe, amusement or neutral condition, all participants were required to watch a video to manipulate the targeted emotion. The three video materials were all clips of about $5 \mathrm{~min}$, and had been adopted in previous research by Piff, Dietze, Feinberg, Stancato and Keltner [18]. The video inducing awe is about grand natural sceneries; the video inducing amusement is about cute animals in the natural environment; the video inducing neutral state is about a man describing the construction of a kitchen countertop; after watching the videos, participants reported their emotional states, including anger, awe, disgust, fear, pride, sadness, happiness and amusement, which were measured by single items ( $1=$ not at all, $7=$ extremely) [18]. Then, participants reported $\mathrm{CN}$ and their likelihoods of engaging in ecological behaviors assessed by same scales employed in Study 2. Finally, all participants were thanked.

\subsection{Results}

We first tested whether the manipulation stimulated the targeted emotion. A one-way ANOVA analysis showed that the ratings of awe in the awe condition were higher than those in the control conditions, $\mathrm{F}(2,267)=222.44, p<0.001$ (see Table 2 and Figure 3). The amusement induction increased amusement relative to the awe and neutral inductions, $\mathrm{F}(2,267)=212.38, p<0.001$ (see Table 2). 


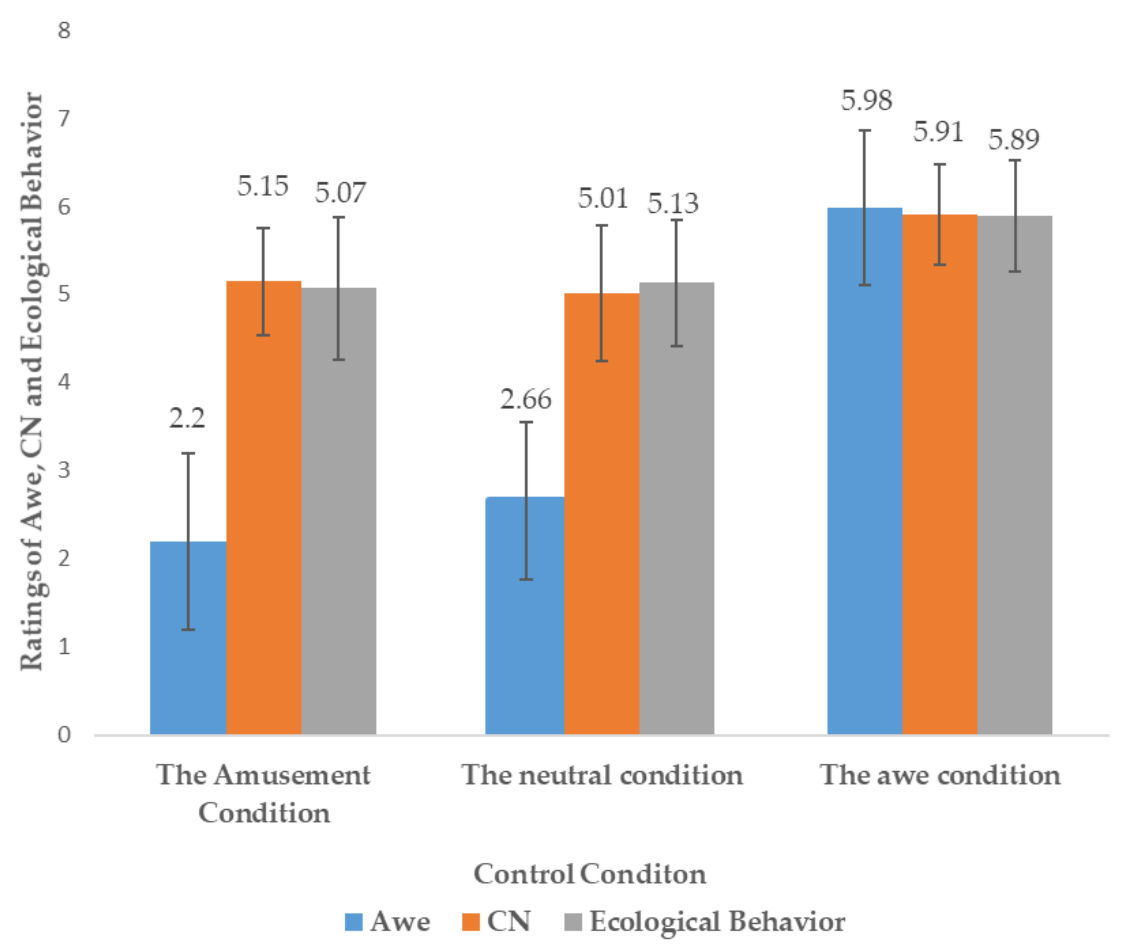

Figure 3. The means and standard deviations of awe, $\mathrm{CN}$ and ecological behavior in Study 3 .

We examined whether the awe emotion significantly increased $\mathrm{CN}$ compared with the control condition. Results of a one-way ANOVA with post hoc analysis indicated that there were significant condition differences. The ratings of $\mathrm{CN}$ in the awe condition $(\mathrm{M}=5.91, \mathrm{SD}=0.57)$ were higher than those in the amusement $(\mathrm{M}=5.15, \mathrm{SD}=0.61)$ and neutral conditions $(\mathrm{M}=5.01, \mathrm{SD}=0.77)$ (See Table 3 and Figure 3). Therefore, the awe induction led to more $\mathrm{CN}$ relative to the other two emotional inductions.

Table 3. Between-group differences in $\mathrm{CN}$ and ecological behavior.

\begin{tabular}{ccccc}
\hline & & \multicolumn{2}{c}{ Post-Hoc Statistics [95\% CI Mean Difference] } \\
\cline { 3 - 5 } & ANOVA & $\begin{array}{c}\text { Awe-Neutral } \\
\text { Condition }\end{array}$ & $\begin{array}{c}\text { Awe-Amusement } \\
\text { Condition }\end{array}$ & $\begin{array}{c}\text { Amusement-Neutral } \\
\text { Condition }\end{array}$ \\
\hline \multirow{2}{*}{$\mathrm{CN}$} & $\mathrm{F}(2235)=11.87 ;$ & $p=0.000 ;$ & $p=0.000 ;$ & $p=0.829 ;$ \\
& $p=0.000$ & {$[0.23,0.76]$} & {$[0.29,0.76]$} & {$[-0.25,0.31]$} \\
Ecological & $\mathrm{F}(2235)=24.37 ;$ & $p=0.000 ;$ & $p=0.000 ;$ & $p=0.686 ;$ \\
Behavior & $p=0.000$ & {$[0.44,0.90]$} & {$[0.42,0.83]$} & {$[-0.29,0.19]$} \\
\hline
\end{tabular}

We then tested whether the awe emotion significantly increased ecological behavior relative to the control emotion. A one-way ANOVA with post hoc analysis showed that there were significant condition differences. The awe emotion led to increased ecological behavior $(\mathrm{M}=5.89, \mathrm{SD}=0.63)$, compared with amusement $(\mathrm{M}=5.07, \mathrm{SD}=0.81)$ and neutral states $(\mathrm{M}=5.13, \mathrm{SD}=0.72)$ (See Table 3 and Figure 3). Therefore, the awe induction enhanced ecological behavior relative to the amusement or neutral induction.

In addition, we examined the correlation between $\mathrm{CN}$ and ecological behavior. The results indicated that $\mathrm{CN}$ was positively associated with ecological behavior, $r=0.73 ; p=0.000$.

Finally, a bootstrap mediation analysis, recommended by Preacher and Hayes [43,44], was conducted to ascertain the mediating effect of $\mathrm{CN}$ on the relationship between awe and ecological behavior. The condition was coded as 1 (awe), 0 (neutral) or -1 (amusement). As shown in Figure 4, with 5000 bootstrap iterations, the indirect influence of awe on ecological behavior via $\mathrm{CN}$ was 
significant, 95\% CI [0.04, 0.50]. Moreover, the results indicated that the direct influence of the awe condition (in contrast to the control condition) on ecological behavior became nonsignificant when $\mathrm{CN}$ was included in the model, $95 \%$ CI $[-0.02,0.40]$ (see Figure 4). All the findings indicated that CN fully mediated the influence of awe on the promotion of ecological behavior.

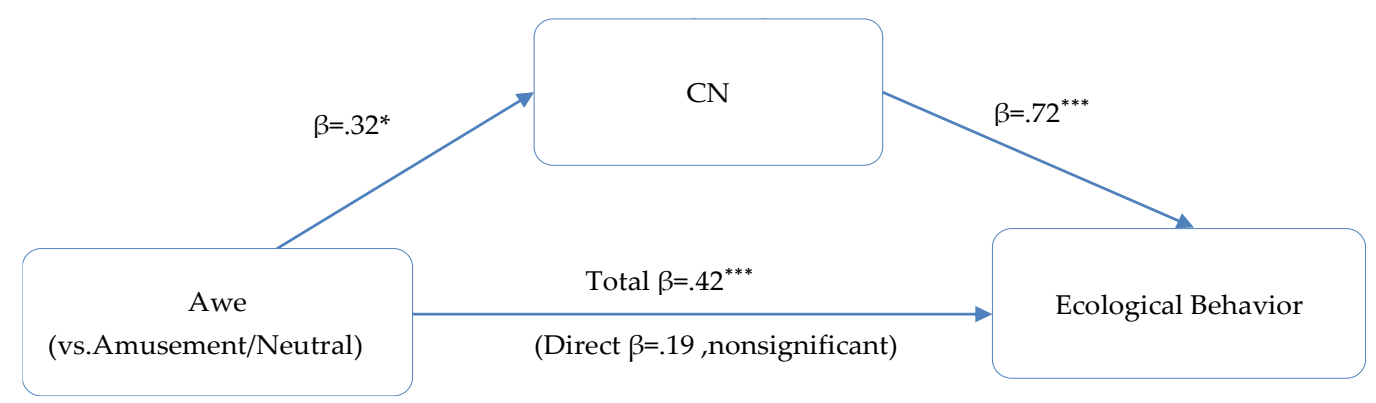

Figure 4. The mediating role of connectedness to nature in Study 3. Note: Unstandardized coefficients are shown. ${ }^{*} p<0.05 ;{ }^{* * *} p<0.001$.

\subsection{Discussion}

These results further supported that $\mathrm{CN}$ mediated the effect of awe on ecological behaviors. Compared with people in the control context, participants in the awe condition reported more $\mathrm{CN}$ and showed more possibilities to behave ecologically. The results were consisted with the previous prediction that $\mathrm{CN}$ accounted for the effect of awe on ecological behavior.

\section{General Direction}

People have a strong instinctive demand for $\mathrm{CN}$ named biophilia [45]. $\mathrm{CN}$ is beneficial for human beings, as well as for environmental protection [46]. However, with the development of technologies and increased urbanization, accompanied by the isolation from outdoor natural environmental stimuli in civic life, this essential type of connectedness seems to have been undermined. This dilemma inspires us to investigate whether people would increase $\mathrm{CN}$ following awe, a specific self-transcendent positive emotion that involves the inclusion of other entities in one's self-concept, and whether increased CN following awe promotes ecological behaviors.

The results of the three experiments revealed that individuals experiencing the awe emotion increased their likelihoods of behaving ecologically (Study 1 and 2) and prompted CN (Study 2). $\mathrm{CN}$ played a mediating role in the influence of awe on ecological behavior (Study 3). Overall, all results support the hypothesis that awe increased ecological behavior due to $\mathrm{CN}$ induced by awe.

The findings of this paper are consistent with previous related studies on the social function of the awe emotion $[18,47]$. In these investigations, awe is confirmed to increase prosociality and collective engagement [18], promotes integration into social groups [48], and decreases aggression [47]. The paper extends this function to ecological behavior. Although both prosocial behavior and ecological behavior are relevant to the broadening of self-concept, the prosocial behavior is distinct from the ecological behavior. Prosocial behavior is relevant to connectedness to other human beings, embracing others in the self-concept, while our findings prove that ecological behavior involves connectedness to nature; the inclusion of the whole of nature into the self. The latter would be concerned with a broader scope of self-concept. These researchers unanimously explained the relationship between awe and various selfless behavior in terms of people's sense of small self. This paper further showed that awe could also bring out increased desires for $\mathrm{CN}$, which in turn prompted pro-environment behaviors.

\section{Implications}

Our paper contributes to the previous theory and management practice in the following three aspects. First, the discussion on the antecedents of ecological behavior almost all focus on extrinsic 
factors in previous research $[9,49]$, rarely addressing the intrinsic mechanisms that underlie ecological behavior [5]. Ecological behavior refers to the sacrifice of the short-term interests of the individual in exchange for the overall interests of the public and society [5]. Although the rational cognition for the cost-benefit tradeoff seems to the main reason for the gap between ecological awareness and practical behavior, emotional variables are confirmed to exert a more significant influence in environmental related behavior than cognitive variables [9,49]. We further verify the key influence of a specific intrinsic emotion-awe-on ecological behavior. Therefore, this study broadens the research on the antecedents of ecological behavior. As compared with extrinsic factors (e.g., demographic variables, ecological awareness) discussed in previous research, the awe emotion could be easily manipulated and affected, so the findings present a new direction to prompt ecological behavior in daily life. For public managers, in addition to publish targeted regulations and policies to protect environment, flexible methods combined with the awe emotion can be adopted, such as charitable activities, propaganda, and carrying forward outstanding environmental personalities.

Second, the self-transcendent value undermines the focus on the self and prioritizes the welfare of external existence [5]. Specifically, this value leads to intrinsic motives to protect the environment $[34,35]$, while suppressing values that support self-interest. The emotion of awe is deemed to be one typical self-transcendent experience [36]. Hence, people experiencing awe should show intrinsic motives to care for the environment. However, the majority of related studies just confirm repeatedly that awe can inspire the small self, as well as being concerned with social psychological and behavioral results, such as increased social value orientation, collective engagement and decreased aggression. The discussion on the effect of awe on the relationship between the self and the natural world is rarely mentioned. Our study extends the research on awe and further confirms that awe has a natural impact on the individual's CN, resulting in a lack of distinctness of the perceived boundaries between humans and the natural world. These findings not only deepen the mechanisms of awe on the self, but also provide a new insight for comprehending individuals' association with the natural world.

Third, the present findings further corroborate that awe could also advance pro-environment actions via $\mathrm{CN}$. If there is no close connection between people and nature, it is hard for people to conduct ecological practice voluntarily in daily life because ecological behavior must be done at the cost of economy, convenience, and comfort [5]. Our study contributes to the mechanisms of the effect of awe on ecological behavior by showing $\mathrm{CN}$ to be an indicator of broad self-concept, effectively explaining the influence of awe on ecological behavior. Based on these results, public managers could effectively guide ecological behavior by means of activities that promote the feeling of harmony and connection between people and nature.

\section{Limitations}

Similar to the majority of the related studies, the two types of awe we focus on in the present research play identical roles as dependent variables. Consequently, analysis of the differences between the two types of awe has been neglected, and needs further investigation. Therefore, future studies should extend our findings concerning the different impacts of various types of awe on ecological behavior. In addition, this article only chose college students as the sample, excluding other social respondents; the limitations of sample selection may make the conclusions of this article narrower.

\section{Conclusions}

$\mathrm{CN}$ is an intrinsic orientation in people's minds and a vital feature for environmental protection. However, to date, only few studies have addressed diverse ways to enhance $\mathrm{CN}$ and ecological behavior. The investigation conducted in this study indicates that awe, although often scarce and fleeting, serves a vital ecological function. When people feel awe, the feeling of $\mathrm{CN}$ increases, which in turn prompts the inclination of ecological behavior. 
The present research also carries theoretical and practical implications for the crucial role of the awe emotion in one's coping with nature and the environment. With increasing deterioration of the global environment, it is critical for scholars, industries and governments to take effective action to enhance people's pro-environmental concerns and ecological behaviors, the findings would provide another way to fulfill their need.

Author Contributions: Conceptualization, Y.Y. and F.J.; Data curation, J.H.; Formal analysis, J.H.; Funding acquisition, Y.Y. and F.J.; Investigation, Y.Y. and J.H.; Methodology, J.H.; Project administration, Y.Y. and F.J.; Writing - original draft, Y.Y. and J.H.; Writing - review \& editing, Y.Y., J.H. and B.N.

Funding: This research was funded by National Natural Science Foundation of China (71772064).

Conflicts of Interest: The authors declare no conflict of interest.

\section{References}

1. Cho, Y.; Soster, R.; Burton, S. Enhancing environmentally conscious consumption through standardized sustainability information. J. Consum. Aff. 2017, 1-22. [CrossRef]

2. Fraj, E.; Martinez, E. Influence of personality on ecological consumer behaviour. J. Consum. Behav. 2006, 5, 167-181. [CrossRef]

3. Ministry of Ecology and Environment of the People's Republic of China (MEEPRC). National Survey of the Chinese Ecological Civilization. Available online: http:/ / www.zhb.gov.cn/xxgk/hjyw/201403/t20140325_ 269661.shtml (accessed on 15 June 2018).

4. Kollmuss, A.; Agyeman, J. Mind the gap: Why do people act environmentally and what are the barriers to pro-environmental behavior? Environ. Educ. Res. 2002, 8, 239-260. [CrossRef]

5. Miniero, G.; Codini, A.; Bonera, M.; Corvi, E.; Bertoli, G. Being green: From attitude to actual consumption. Int. J. Consum. Stud. 2014, 38, 521-528. [CrossRef]

6. Tam, K.; Chan, H. Environmental concern has a weaker association with pro-environmental behavior in some societies than others: A cross-cultural psychology perspective. J. Environ. Psychol. 2017, 53, 213-223. [CrossRef]

7. Rudd, M.; Vohs, K.D.; Aaker, J. Awe expands people's perception of time, alters decision making, and enhances well-being. Psychol. Sci. 2012, 23, 1130-1136. [CrossRef] [PubMed]

8. Saroglou, C.P.V. Awe's effects on generosity and helping. J. Posit. Psychol. 2016, 11, 1-9.

9. Cheung, W.Y.; Luke, M.A.; Maio, G.R. On attitudes towards humanity and climate change: The effects of humanity esteem and self-transcendence values on environmental concerns. Eur. J. Soc. Psychol. 2014, 44, 496-506. [CrossRef]

10. Davis, J.L.; Le, B.; Coy, A.E. Building a model of commitment to the natural environment to predict ecological behavior and willingness to sacrifice. J. Environ. Psychol. 2011, 31, 257-265. [CrossRef]

11. Poon, K.T.; Teng, F.; Chow, J.T.; Chen, Z. Desiring to connect to nature: The effect of ostracism on ecological behavior. J. Environ. Psychol. 2015, 42, 116-122. [CrossRef]

12. Gosling, E.; Williams, K.J.H. Connectedness to nature, place attachment and conservation behaviour: Testing connectedness theory among farmers. J. Environ. Psychol. 2010, 30, 298-304. [CrossRef]

13. Restall, B.; Conrad, E. A literature review of connectedness to nature and its potential for environmental management. J. Environ. Manag. 2015, 159, 264-278. [CrossRef] [PubMed]

14. Liefländer, A.K. Effectiveness of environmental education on water: Connectedness to nature, environmental attitudes and environmental knowledge. Environ. Educ. Res. 2015, 21, 145-146. [CrossRef]

15. Mayer, F.S.; Frantz, M.P. The connectedness to nature scale: A measure of individuals' feeling in community with nature. J. Environ. Psychol. 2004, 24, 503-515. [CrossRef]

16. Beery, T.; Jönsson, K.I.; Elmberg, J. From environmental connectedness to sustainable futures: Topophilia and human affiliation with nature. Sustainability 2015, 7, 8837-8854. [CrossRef]

17. Shiota, M.N.; Keltner, D.; Mossman, A. The nature of awe: Elicitors, appraisals, and effects on self-concept. Cognit. Emot. 2007, 21, 944-963. [CrossRef]

18. Piff, P.K.; Dietze, P.; Feinberg, M.; Stancato, D.M.; Keltner, D. Awe, the small self, and prosocial behavior. J. Personal. Soc. Psychol. 2015, 108, 883-899. [CrossRef] [PubMed] 
19. Baumeister, R.F.; Leary, M.R. The need to belong: Desire for interpersonal attachments as a fundamental human motivation. Psychol. Bull. 1995, 117, 497-529. [CrossRef] [PubMed]

20. Capaldi, C.A.; Dopko, R.L.; Zelenski, J.M. The relationship between nature connectedness and happiness: A meta-analysis. Front. Psychol. 2014, 5, 976. [CrossRef] [PubMed]

21. Schultz, P.W.; Tabanico, J. Self, identity, and the natural environment: Exploring implicit connections with nature. J. Appl. Soc. Psychol. 2010, 37, 1219-1247. [CrossRef]

22. Nisbet, E.K.; Zelenski, J.M.; Murphy, S.A. Happiness is in our nature: Exploring nature relatedness as a contributor to subjective well-being. J. Happiness Stud. 2011, 12, 303-322. [CrossRef]

23. Frumkin, H. Beyond toxicity: Human health and the natural environment. Am. J. Prev. Med. 2001, 20, 234-240. [CrossRef]

24. Keltner, D.; Haidt, J. Approaching awe, a moral, spiritual, and aesthetic emotion. Cognit. Emot. 2003, 17, 297-314. [CrossRef] [PubMed]

25. Bonner, E.T.; Friedman, H.L. A conceptual clarification of the experience of awe: An interpretative phenomenological analysis. Humanist. Psychol. 2011, 39, 222-235. [CrossRef]

26. Lu, D.; Liu, Y.; Lai, I.; Yang, L. Awe: An important emotional experience in sustainable tourism. Sustainability 2017, 9, 2189. [CrossRef]

27. Lee, K.; Ashton, M.C.; Choi, J.; Zachariassen, K. Connectedness to Nature and to Humanity: Their Association and Personality Correlates. Front. Psychol. 2015, 6, 1-11. [CrossRef] [PubMed]

28. Leary, M.R.; Tipsord, J.M.; Tate, E.B. Allo-inclusive identity: Incorporating the social and natural worlds into one's sense of self. In Transcending Self-Interest: Psychological Explorations of the Quiet Ego; Wayment, H.A., Bauer, J.J., Eds.; APA: Washington, WA, USA, 2008; pp. 137-147.

29. Tam, K.P. Concepts and measures related to connection to nature: Similarities and differences. J. Environ. Psychol. 2013, 34, 64-78. [CrossRef]

30. Kunchamboo, V.; Leem, C.K.C.; Brace-Govan, J. Nature as extended-self: Sacred nature relationship and implications for responsible consumption behavior. J. Bus. Res. 2017, 74, 126-132. [CrossRef]

31. Cojuharenco, I.; Cornelissen, G.; Karelaia, N. Yes, I can: Feeling connected to others increases perceived effectiveness and socially responsible behavior. J. Environ. Psychol. 2016, 48, 75-86. [CrossRef]

32. Davis, J.L.; Green, J.D.; Reed, A. Interdependence with the environment: Commitment, interconnectedness, and environmental behavior. J. Environ. Psychol. 2009, 29, 173-180. [CrossRef]

33. Aron, A.; Aron, E.N. Love as the Expansion of Self: Understanding Attraction and Satisfaction; Hemisphere: New York, NY, USA, 1986.

34. Nilsson, A.; Borgstede, C.V.; Biel, A. Willingness to accept climate change strategies: The effect of values and norms. J. Environ. Psychol. 2004, 24, 267-277. [CrossRef]

35. Slimak, M.W.; Dietz, T. Personal values, beliefs, and ecological risk perception. Risk Anal. 2010, 26, $1689-1705$. [CrossRef] [PubMed]

36. Stellar, J.E.; Gordon, A.M.; Piff, P.K.; Cordaro, D.; Anderson, C.L.; Bai, Y.; Maruskin, L.A.; Keltner, D. Self-transcendent emotions and their social functions: Compassion, gratitude, and awe bind us to others through prosociality. Emot. Rev. 2017, 9, 200-207. [CrossRef]

37. Frantz, C.; Mayer, F.S.; Norton, C.; Rock, M. There is no "I" in nature: The influence of self-awareness on connectedness to nature. J. Environ. Psychol. 2005, 25, 427-436. [CrossRef]

38. Sivanathan, N.; Pettit, N.C. Protecting the self through consumption: Status goods as affirmational commodities. J. Exp. Soc. Psychol. 2010, 46, 564-570. [CrossRef]

39. Gordon, A.M.; Stellar, J.E.; Anderson, C.L.; McNeil, G.D.; Loew, D.; Keltner, D. The dark side of the sublime: Distinguishing a threat-based variant of awe. J. Personal. Soc. Psychol. 2016, 113, 310-328. [CrossRef] [PubMed]

40. Bissing-Olson, M.J.; Fielding, K.S.; Iyer, A. Experiences of pride, not guilt, predict pro-environmental behavior when pro-environmental descriptive norms are more positive. J. Environ. Psychol. 2016, 45, 145-153. [CrossRef]

41. Zelenski, J.M.; Dopko, R.L.; Capaldi, C.A. Cooperation is in our nature: Nature exposure may promote cooperative and environmentally sustainable behavior. J. Environ. Psychol. 2015, 42, 24-31. [CrossRef]

42. Kaiser, F.G.; Doka, G.; Hofstetter, P.; Ranney, M.A. Ecological behavior and its environmental consequences: A life cycle assessment of a self-report measure. J. Environ. Psychol. 2003, 23, 11-20. [CrossRef] 
43. Preacher, K.J.; Hayes, A.F. SPSS and SAS procedures for estimating indirect effects in simple mediation models. Behav. Res. Methods Instrum. Comput. 2004, 36, 717-731. [CrossRef] [PubMed]

44. Preacher, K.J.; Hayes, A.F. Asymptotic and resampling strategies for assessing and comparing indirect effects in multiple mediator models. Behav. Res. Methods 2008, 40, 879-891. [CrossRef] [PubMed]

45. Kellert, S.R.; Wilson, E.O. The Biophilia Hypothesis; Bioscience: Washington, WA, USA, 1993.

46. Zhang, J.W.; Howell, R.T.; Iyer, R. Engagement with natural beauty moderates the positive relation between connectedness with nature and psychological well-being. J. Environ. Psychol. 2014, 38, 55-63. [CrossRef]

47. Yang, Y.; Yang, Z.; Bao, T.; Liu, Y.; Passmore, H. Elicited Awe Decreases Aggression. J. Pac. Rim Psychol. 2016, 10, 1-13. [CrossRef]

48. Bai, Y.; Maruskin, L.A.; Chen, S.; Gordon, A.M.; Stellar, J.E.; Mcneil, G.D.; Peng, K.; Keltner, D. Awe, the diminished self, and collective engagement: Universals and cultural variations in the small self. J. Personal. Soc. Psychol. 2017, 113, 185-209. [CrossRef] [PubMed]

49. Chan, R.Y.K. Determinants of Chinese Consumers' Green Purchase Behavior. Psychol. Mark. 2001, 18, 389-413. [CrossRef]

(C) 2018 by the authors. Licensee MDPI, Basel, Switzerland. This article is an open access article distributed under the terms and conditions of the Creative Commons Attribution (CC BY) license (http:/ / creativecommons.org/licenses/by/4.0/). 